\title{
Ciudades en paralelo. Cartagena y Veracruz
}

\section{Cities in parallel. Cartagena and Veracruz}

\author{
Bernández, Carmen, Noelle louise Guy Burgel y Pedro C.
} Sonderéguer (Dirs.) (20I3), CARThagĖNe-VERACRUZ. VILLES-PORTS DANS la mundialisation, Universidad Autónoma Metropolitana, MÉXICO, 482 PP., ISSN 0242-2794

Para el estudioso de los temas territoriales e incluso para el viajero ocasional o el ciudadano interesado en los lugares excepcionales así como en la historia y morfología de sus ciudades, los cambios registrados en el orden cronológico de las urbes no son evidentes sino que permanecen encriptados, no adormecidos sino algo silentes, actualizando su presencia y reclamando su futuro. Por ello, resulta importante este nuevo texto, escrito en español y en francés e inscrito en la irreversible mundialización de la economía, en sus contradicciones y desajustes, en él se trata de entrever a Veracruz, México y Cartagena de Indias, Colombia a partir de sus recuerdos y sus reencuentros: el mar de cerca, toda su gente de ayer y hoy, sus puertos -ventana entre dos mundos y su cultura-, siempre vigentes, con sus productos y enfermedades, riesgos contados por navegantes, gente que supo entender, sortear el clima y las adversidades.

\section{¿Cómo abordar las dificultades que propone el tiempo, la distancia y la diferencia?}

Un grupo de especialistas mexicanos y franceses aportan su visión, con disciplina y oficio, para mostrar con buenas descripciones, bellas imágenes y testimonios relevantes, el parentesco y, a la vez, diversidad en los caminos de Veracruz y Cartagena que han recorrido en sus andanzas. A partir de la conquista espańola, el coloniaje, los mestizajes, piedra tras piedra, los intereses, héroes honrados, otros sin nombre dejando huellas entre la tierra, el mismo mar y su inmensidad, obras portuarias, calles que crecen, sonidos claros, la educación, salud, fiestas y siestas, llegan como ecos a la conciencia.

Un urbanismo elegante, apoyado en el método comparativo de orientación sociológica, aunque sin dejar de incluir vivencias y observaciones de individuos conocedores del tema y los problemas, permite situar los hechos, reconstruir las edificaciones y dar sentido a las acciones pasadas 
y presentes para restituir lo ausente, dar paso a lo actual y a lo que vendrá con riesgo, pero mostrando los paralelos, cruces frecuentes, desorden e interminables cantos y leyendas; modernidad harto inconclusa dejando restos, lo cierto e incierto, las paradojas, cartas al viento; presencias entre los muros de otras historias, varios sentidos, viejos navíos con sus tesoros para encontrarse con la mujer india, desnuda, innominada y muchos otros seres que someter y vigilar. También dejar que la naturaleza pueda acceder a tantos cambios, usos y abusos que acometer, para saber, a fin de cuentas, si es que es posible la convivencia, coevolución y ese retorno a lo imposible de lo real dado.

Así, la narrativa empieza por la cartografía: mapas y estadísticas, líneas y cifras delimitando los espacios y sus procesos sociales causantes; los fractales, imprescindibles para situar la tierra austera; lo construido, sus caminos, asentamientos, los habitantes, tantos por cientos, comparativos muy elocuentes, entre los que destacan: Cartagena en 2011 contaba ya con más de 900 mil censados; mientras que Veracruz estaba habitado en 2010 por 550 mil.

Acto seguido, el texto reconoce que Cartagena, en el Caribe, fue hito privilegiado para los viajeros, desdes ahí se sucitaba el control de mares y las estrategias. Pero no duró mucho la gloria y las carabelas se fueron con la decaída, mostrando en todo que no bastaba la voluntad de poder para hacerla vivir, ya que mar adentro su irrelevante papel la condenó como fortaleza, plataforma abierta entre el Viejo y el Nuevo Mundo.

Hoy, sin embargo, hay esperanza, expectativa de nuevos vientos para que los intercambios puedan hacer girar a todo el Caribe y, entre sus cambios, la Cartagena vuelva a brillar. Son varios siglos de gran trabajo: están los muelles, grúas potentes, sitios para atracar, hay terminal para conectar, muchas maniobras y embarcaciones a diario llegan. ¿ Será que ahora con el comercio internacional habrá otros sitios, vínculos nuevos tanto en América como en Europa que hasta el Oriente puedan llegar?

Afirma Pedro Conrado Sonderéguer, uno de los autores, que la incipiente apertura de Cuba, especialmente en su puerto de Mariel, aparece con suficiente sentido, como el símbolo de la renovación de la isla y su reincorporación al tráfico del Caribe. Y es también en este posible escenario que la mirada sobre los puertos de Cartagena y Veracruz cobra significación, sobre todo si se recupera el anterior equilibrio del Caribe y su rol histórico de lugar de encuentro global. De ahí que esta especie de Mediterráneo americano estaría en posibilidad de sacar partida de sus tradiciones y mestizajes y generar múltiples trueques: cruce de culturas, tierra de innovaciones y mitos, no del todo saturados por la razón pragmática; zona de encuentros pasados y presentes, promesas en espera. 
¿Cómo desestabilizar las inercias que ocultan los verdaderos tesoros nunca perdidos?

Con el fin de las luchas ideológicas y políticas del mundo bipolar y las batallas internas por la libertad y dignidad, Cuba, la ausente y desterrada es la buena nueva, otro proyecto Mariel despega, no sin problemas, pero sí hacia otro esquema, no hay panacea, hay un tema: que el territorio pueda volver a ser la fuerza, la evolución. ¿¿Será que entonces, de nuevo el mar traerá sorpresas, moverá conciencias y voluntades para pactar?

Como parte vital de su sistema de defensa el Caribe, Cartagena y Veracruz sí surgieron con un origen similar consistente en ciudades amuralladas y abaluartadas que se erigieron para hacer frente a los piratas, pero además soberbios puertos en las rutas de comercio y navegación; lo que exigió tanto la reproducción de modelos europeos de ingeniería y arquitectura militares, como la interpretación de los tratados militares de la época. Y eso lo vemos también en Campeche, La Habana, San Juan, Santo Domingo, Panamá, Portobelo y Veracruz.

En efecto, se trató de una adaptación de la teoría tratadística a las circunstancias regionales y ambientales de los territorios conquistados, lo que definió la organización territorial así como los emplazamientos urbanos, orquestando a la vez el crecimiento de las ciudades a partir de los recintos amurallados. Y es que el fantasma de Francis Drake, el legendario pirata inglés, aún vaga por San Juan de Ulúa donde, por cierto, se le rechazó en 1568, pero a Cartagena sí la devastó, por lo que Felipe II ordenó ambas fortificaciones.

Cierto es que los orígenes de tal arquitectura defensiva datan de la Grecia Antigua y posteriormente de Roma, estas características constructivas se muestran claramente en las ciudades medievales con los castillos enclavados en lo alto de los territorios y desde luego en las iglesias, con sus torres espigadas regían la composición y los trazos irregulares podían cambiar drásticamente. Hasta que en el Renacimiento, y ya contando con la pólvora, se buscaron soluciones para establecer los sitios ideales para los emplazamientos urbanos según las particularidades de la ciudad a fundar y defender.

En síntesis, si bien no existió un modelo repetitivo en la solución arquitectónica, en cuanto a Cartagena de Indias y Veracruz, sus rasgos corresponden al cambio de estructura defensiva por los nuevos métodos y técnicas de acometida que exigió el Renacimiento. Los proyectos iniciales de defensa obedecieron a la integración de las formas medievales con la abstracción geométrica racional que combinaron eficazmente la escuela italiana y la ingeniería espańola. La figura principal del ingeniero militar Bautista Antonelli aportó a sus seguidores un conjunto de estructuras simétricas, terraceadas, dominando la escala monumental con elementos 
compositivos proporcionales entre las partes y el conjunto que lo único que las distingue de las demás es la armonía con el contexto, y las soluciones para librar el alcance de las armas de fuego, además de las normas defensivas que dictaban los tratados militares de entonces.

Un salto histórico plenamente justificado nos conduce a repensar, primero, la situación de Cartagena en el siglo XIX, centrando el punto en las consecuencias del federalismo y la desamortización de los bienes. Para entonces, era un activo puerto que actuaba en forma sobre el Caribe y el comercio interior, de ahí que los bienes urbanos se concentraron en esa ciudad. Para finales de esa centuria podía hablarse del renacimiento de Cartagena con la incorporación de espacios construidos allende las murallas: se trataba de la transición entre la lógica medieval y la moderna, cuando pisó fuerte la figura del entonces presidente de Colombia, Rafael Núñez (oriundo de Cartagena), quien impulsó la reedificación de casas, mejora de barrios, movido por los modelos representativos del progreso que le inspiraron sus estancias en París, tomando imágenes de Notre Dame y la catedral de Milán, en su estilo gótico. Se buscó el ornato o embellecimiento urbano, con lo que llegaron los parques, la transformación de los servicios de infraestructura, la electricidad, incluso un acueducto pero, sobre todo, la línea férrea: era el tránsito de las precariedades a la ciudad moderna.

En segundo término, vienen las imágenes y recuento de los hechos en Veracruz a finales del siglo xix, en el cotejo y los contrastes de una ciudad portuaria. No sobra afirmar que si fue básico ese sitio para la Nueva España, igualmente resultó su jerarquía para el México independiente del mundo atlántico y asimismo referente mundial en comercio e intercambios culturales. Un dato no bien sabido, la vagabunda Veracruz, ya que fueron cuatro los intentos de su fundación hasta que por fin quedan instaladas frente al islote de San Juan de Ulúa, con unas cuantas casashabitación, varias posadas y bodegas fortificadas en 1793 .

Durante el siglo XIX se da el proceso de modernización urbana, bajo la visión liberal, cuando llegan al fin las corrientes higienistas y se define el modelo de desarrollo nacional, donde puertos y fronteras recibieron mejoras, y las decisiones de Porfirio Díaz llegan al puerto, con su basta obra material: el ferrocarril, llevándose en derrumbe la muralla al mar. Impulsando el nuevo esquema de zona portuaria, es decir, combatiendo la precariedad y atacando las incesantes enfermedades tropicales, ya que el medio y el clima eran propicios para toda clase de epidemias, tanto en muelles como en las aduanas: se trataba de ganarle terrenos al mar, luchas contra la escasez de agua potable, las constantes inundaciones; pero también, urbanizar el puerto, con alumbrados públicos. 
Para imponer este progreso fue necesaria la paz y el orden, mejoras en la educación y la cultura, llegaron los adelantos científicos y la bonanza en las instituciones hospitalarias, avance sí, aunque marcaron los límites y alcance de la modernidad urbana en una ciudad que luchaba a hombro partido contra las enfermedades como el cólera, la viruela, el sarampión y la fiebre amarilla. Pasado el peligro e iniciado el siglo xx podía escucharse que en Veracruz, el dictador hablaba entonces de la pompa y circunstancia para mostrar al mundo entero lo que el positivismo podía lograr cuando de modernización se trataba.

Como paréntesis en el tema central, dos entrevistas traen al pensamiento del lector otros hechos relevantes. Por un lado, la aparente paradoja de cómo, en general, mientras que las revoluciones de independencia fueron urbanas, las del siglo xx tuvieron su epicentro en el medio rural, mostrando así pautas de desarmonía y discordancias; además del componente ideológico, ya que, principalmente en América Latina, campearon las guerrillas rurales y los movimientos agrarios que parecían a contracorriente de las tendencias a la urbanización-industrialización y sus secuelas.

$Y$ es que en la ciudad, afirma Guy Burgel, predominaba el orden pero a la vez la anarquía, el anonimato, la embestida de las masas. Lo que muestra la complejidad urbana, donde no existen las ciudades completamente reguladas sino la inestabilidad junto a la democracia, por lo que se requería más de la eficacia moral y no sólo la proclamación de los valores éticos. Por ello, insiste el pensador-investigador, en la mayoría de los casos de esa urbanización modernizante, resalta la exuberancia e inmediatez de un idealismo (imposible). De ahí que concluya el especialista: "importa menos la cosa observada que la manera de analizar la ciudad” (137).

Por su parte, la entrevista a Marcel Roncayolo ilustra y recuerda que para comprender mejor la situación de Cartagena y Veracruz como dos puertos de gran trascendencia a partir del siglo XVI -sitios de donde partían los productos, especialmente el oro y la plata de América Latina- habría que volver, ante todo, a la geografía en lo relativo a la especificidad de los lugares, lo que eventualmente tendría que asociarse con la noción de legado.

Recordar, entonces que en un principio Marsella fue un importante puerto de Grecia anexado al Imperio romano por Julio César en el año 49 a. C., que conservó la traza original y sus nexos con el comercio mediterráneo, y así se mantuvo toda la Edad Media hasta su incorporación al reino de Francia en el siglo xv, lo que derivó en murallas de resguardo. Por lo que, apunta el autor, se requiere volver a consideraciones que ligan la cuestión del legado, ámbito donde la arquitectura y el urbanismo generaron durante los últimos siglos relevantes casos de estudio tanto en los puertos de América como en Europa. Sin embargo, en tiempos de la 
modernidad y después de la fuerte especulación con los nuevos espacios del puerto, la tensión provocada disminuyó con importantes obras urbanas, desde luego para los barrios residenciales en el puerto. Y de igual manera, como lo había hecho el arquitecto Haussmann en París, desarrollaron la estación del ferrocarril, que a la vez cumple la función de elemento destructor como barrera de elementos urbanos, también contribuye a la valorización de barrios urbanos; pero el proyecto nunca quedó bien terminado, provocando en Marsella una crisis interminable, ilustrando así el famoso distanciamiento entre la ciudad y el puerto, típico de las redes ferroviarias mediterráneas.

El punto de enlace con el tema del libro radica en que ese puerto comercial tenía gran interés por el Caribe, toda vez que varias de sus islas fueron colonias francesas. Por esa vía, los dos principales puertos del Caribe, Veracruz y Cartagena estuvieron también vinculados comercialmente con Marsella, y más aún después de la independencia de las colonias españolas. Este caso, no obstante, a pesar de diferir por situarse más cerca del imperio que de la periferia, como sí lo eran las de Latinoamérica, resaltaba por ser extrema la desarticulación entre ciudad y puerto, si bien compartían las tres una fachada marítima y su condición urbana que las presenta cortadas por el mar y por el puerto, o sea, la forma asimétrica en su composición.

Entonces, destaca en la entrevista que siendo principal el lazo comercial de Marsella con Veracruz y Cartagena, sobre todo en los siglos xix y $\mathrm{xx}$, ese vínculo dejó huellas en la zona americana y riquezas en el área mediterránea. Y es que Marsella había mostrado durante los siglos XVII y XVIII que su progreso dependía más de sus relaciones con Oriente que con África, ya que mucho antes de la construcción del Canal de Suez, que se haría rea lidad cien años después, las mercancías valiosas provenían de China, Indonesia o la India, por la antigua vía oriental.

Se trata, finalmente, de una experiencia histórica que ilustra y comprueba que la conjunción de ciertas lógicas y determinadas presencias posibilitan que algunas acciones se produzcan y la misma concepción del mundo cambie. En lo relativo a América Latina, el conocimiento y deconstrucción de cierta historia, puede dar lugar a un nuevo saber de su pasado y geografía -lejana hoy en Francia-, pero es factible encontrar abundantes estudios que aportan a otra explicación de las múltiples relaciones entre los dos mundos durante los últimos siglos. Por ello, para Roncayolo, México resulta excepcional en documentos y memorias vivas de los nunca interrumpidos lazos con Francia, a pesar del fracaso de Maximiliano.

Las evidencias abundan en intercambios que derivaron en adopciones benéficas para las dos partes, mostrando así cómo las hibridaciones han 
sido y serán formas no sabidas de diálogo-presencia, cuya lógica no determinada a priori avanza como el mar sobre la arena que aparenta contenerla, apaciguarla y entenderla, sin dejar de sentir por un momento que se trata de un pacto que el cambio climático puede alterar, no respetar porque también las geografías se resienten y "hablan" su propia lengua.

El texto avanza con interesantes descripciones de los viajeros europeos y mexicanos, desde el siglo xvi hasta el siglo xx, reconociendo que Veracruz ha sido único en cuanto a mantener su importancia en las relaciones entre el nuevo y el viejo continente, ya que durante más de cuatro siglos han transitado comunicaciones, comercio, noticias y viajeros de mil partes, ya dirigidos a la capital del virreinato de la Nueva España, o en sentido contrario. A pesar de ello, tan importante rol no se refleja en su estructura urbana, orientada a construir una ciudad ordenada, funcional y bella, a similitud de otras tantas poblaciones del país, que a través del tiempo fueron acumulando palacios, iglesias, plazas y callejuelas hasta configurar esos conjuntos que actualmente constituyen el patrimonio cultural de México.

Los antecedentes indican que siempre se ha presentado una continua lucha entre tenacidad y adversidad. Así, la reubicación de la ciudad, promovida por el virrey conde de Monterrey y condicionada por motivos políticos y económicos, ignoró las condiciones geográficas poco aptas del sitio en el que se planeaba asentar la nueva ciudad. A pesar de la oposición de los habitantes, el traslado fue confirmado y realizado finalmente en 1600, y quince años más tarde, por orden de Felipe III, recibía el título de ciudad, con lo que el puerto seguiría desempeñando el papel fundamental de puerta de entrada al virreinato de la Nueva España, confirmándolo a la vez como parada obligatoria para todo aquel que se dirigiera a Europa o hacia la ciudad de México. De ahí que formara parte de las descripciones de soldados, religiosos, aventureros, explotadores o científicos, registradas por medio de narraciones y diarios de viaje, pinturas, grabados y posteriormente fotografías; aunque, en general, dominarán las descripciones de los aspectos pintorescos, curiosos o exóticos más que temas de carácter arquitectónico o urbano.

Un asunto común que aparece en muchas de las relaciones es el asombro y desconcierto en cuanto a que había sido equivocada la elección del lugar para fundar y asentar la ciudad. Por lo que se afirmaba que no había sitio en el Nuevo Mundo cuyo aspecto no satisfaciera las ansias y expectativas de quien llegaba con la intención de avecinarse en la Villa Rica de la Vera Cruz. En efecto, la costa era plana, arenosa y sin vegetación, las casas no tenían tejado y estaban construidas en línea recta, regulares, formando una vasta calle, dando la apariencia de un cementerio. Era, además, uno de los lugares más maléficos y malsanos del mundo. 
El contraste era evidente: no correspondía su falta de calidad urbana con la importancia de las riquezas que por allí transitaban hacia la vieja Europa, mientras que su gente era hospitalaria, generosa y alegre; era también un lugar inhóspito, pues Veracruz no dejaba de padecer el calor sofocante de los veranos, con su secuela de epidemias y tercianas, lo que diezmaba la población, y aunados a los inconvenientes ambientales se agravaban las dificultades para terminar los edificios debido a la poca disponibilidad de buenos materiales de construcción como canteras de piedra o minas de arcilla para la fabricación de ladrillos y tejas, por lo que las iglesias y monasterios fueron construidos de madera, incluso las casas de los hombres más ricos, las rejas y barandas de los balcones y los patios eran de este material, de tal forma que la ciudad fue arrasada muchas veces por los incendios provocados por los fuertes vientos del norte.

Además estaban los inaccesibles costos de la construcción que no se completaba por menos de cientos de miles de dólares, ya que todo tendría que venir del mar. En cuanto a servicios básicos, la gente debía conformarse con el agua que escurría de las dunas o del arroyo Tenoya; el abasto hídrico para consumo doméstico se hacía por medio de aljibes, ubicados en los patios de las casas y de los grandes edificios. La diferencia en el modo de percibir una realidad urbana, entre viajeros extranjeros y mexicanos, entre pintores, grabadores y fotógrafos puede asociarse a la diversidad de puntos de vista, sobre todo en el modo en que los nativos miran y narran su propia ciudad.

La óptica de los forasteros acentúa el impacto cultural entre mundos diversos, el descubrimiento de los factores ambientales y naturales diversos y las tradiciones y costumbres nuevas. De ahí que el estímulo epidérmico, lo exótico, lo pintoresco atraen solamente al extranjero; mientras que en el habitante originario predomina una inspiración que se mueve a través del tiempo en lugar de moverse en el espacio. Por ello es que el libro de viajes escrito por el nativo tendrá siempre cercanía con el libro de memorias.

Cartagena de Indias, por su parte, y en palabras de Beatriz García Moreno, se ostenta como una ciudad de paradojas y contrastes, un sitio de honor que trasciende las ciudades colombianas y latinoamericanas, su Centro Histórico fue reconocido por la Unesco como patrimonio de la humanidad en 1984. Referencia obligada entre los valores patrios, tema de estudio de cronistas, historiadores y literatos, además de un lugar que la modernidad finalmente descubrió, codició y apropió como objeto de un turismo que se divide entre disfrutar lo cultural y bello del paisaje y un mercado mundializado que busca hacerse de ella como parte del botín global.

Ahora bien, su notoriedad se concentra en lo que se ha llamado distrito cultural y turístico, limitado a su Centro Histórico y zonas turísti- 
cas aledańas; mientras que el resto de la ciudad ocupa otro lugar, sin atender, pero que no deja de entrar a hurtadillas en ese primer cuadro de la ciudad, por más que se busque negar su existencia crítica. Su configuración espacial no esconde las lógicas discursivas de los amos en turno, que impusieron sus modelos de poblamiento en medio de difíciles geografías y condiciones humanas que los fueron rebasando. Por ello, su paisaje urbano está lleno de permanencias y contingencias, que muestran una ciudad de rígidos contrastes y de una interesante poética capturada en diversas narraciones.

La ubicación de Cartagena de Indias, que la expone libremente al océano y está resguardada en la misma Bahía de Cartagena, en su exterior e interior, favoreció el acceso para la conquista del continente por la corona española, que la erigió como Portal de las Indias Orientales, favoreciendo asimismo el saqueo y las invasiones de piratas y corsarios representantes de otras coronas europeas, empeñadas todas en luchas por el poder.

Desde tiempos lejanos fue puerto principal para el comercio ultramarino, tanto con Europa como con las Antillas cercanas, convirtiéndose en el mojón necesario para la integración cultural con otras ciudades del Caribe y del continente, que en similares condiciones tuvieron que enfrentar procesos de dominación colonial y cultural, con el consiguiente sometimiento de los pueblos originarios y la esclavitud de los africanos. La otra cara, su proximidad con regiones selváticas permitió en el siglo XVII, el escape de esclavos que abrieron con sus palenques, caminos hacia la libertad. Desde sus inicios y hasta hoy, ha tenido que construir diversas obras de ingeniería y arquitectura para protegerse de los mares de leva, de tempestades y vientos, así como de su frecuente clima extremoso, con temperaturas elevadas y húmedas, solamente menguado por la presencia de vientos alisios entre los meses de noviembre y marzo.

La geografía, con sus accidentes y clima, ha sido tema forzoso de la literatura sobre Cartagena, que no ha dejado de mencionar, entre la narrativa de batallas y prácticas cotidianas, las explanadas y escolleras que la protegen del comportamiento por lo regular despiadado del océano, con sus calles de andenes protegidos por una arquitectura de aleros y balcones, de ventanas de rejas de madera que dejan pasar los vientos, de zaguanes y patios interiores con árboles frutales adecuados para procurar la sombra.

El mapa actual de Cartagena se constituye por trazados de diferentes épocas que se yuxtaponen o interceptan entre sí, mientras que dan cuenta del orden y significación que los concibió, así como de las formas en que han cambiado, apropiado y disfrutado al paso de los nuevos tiempos y los gobernantes con sus gustos y políticas de gobernamentalidad. Su plano vigente, mostrando el centro fundacional, las realizaciones del siglo 
XIX y el crecimiento del siglo xx ofrece una ciudad fragmentada entre una que exhibe la belleza de su condición costera, su historia y su basta estructura turística y, otra, marginada, ajena a la anterior, sumida en la pobreza y sus vicios y dependiente de los trabajos informales derivados del turismo principalmente extranjero. Asimismo, el crecimiento considerable debido al desarrollo de la industria y el comercio, además de las migraciones por las violencias sociopolíticas del país, que exigió la ampliación de la infraestructura y de los servicios, puso al descubierto la inocultable tensión entre los nuevos requerimientos y la historia encerrada en sus arquitecturas.

Aunque Cartagena, extendida por fuera de las murallas, tiene equipamientos para la movilidad, como el aeropuerto, la terminal de transportes terrestres y el terminal marítima, sus instalaciones no son del todo adecuadas. Finalmente, puede decirse que Cartagena hoy es un paisaje entre aguas de diversas formas y tonos, que su área urbana se expande entre las tensiones que ofrece un pasado contundente y un presente que se ha ido acomodando a los requerimientos locales, así como a las del turismo internacional que pretende apropiarla mientras muchos de sus sectores se hunden en la pobreza, que su cotidianidad sucede entre la Cartagena cosmopolita de visitantes extranjeros y la de los residentes originarios de culturas ancestrales que circulan por en sus calles y playas, con su color y sudor, llevando a cuestas sus tradiciones.

Acompañan y complementan esta monumental obra los apartados para hablar de la traza urbana de Veracruz; las historias de campesinos franceses de Jicaltepec y San Rafael. Además de las huellas de la presencia de África en Cartagena de Indias y su entorno; la cumbia y leyendas sobre la fiebre de exportación. Lugar especial para hablar de los proyectos de preservación patrimonial y desarrollo urbano, arquitectura y modernidad, tanto para Veracruz como para Cartagena, la cuestión ambiental y bellos grabados de Veracruz, con atinados y bellos textos que le otorgan dimensión y calidez.

Recibida: 30 de junio de 2014. Aceptada: 3 de julio de 2014.

José María Aranda Sánchez Universidad Autónoma del Estado de México Correo-e: arandasjm@gmail.com

José María Aranda Sánchez. Mexicano. Es doctor en urbanismo. Actualmente es profesor-investigador de la Facultad de Artes de la Univer- 
sidad Autónoma del Estado de México. Su línea de investigación actual es sociología de la cultura. Entre sus últimas publicaciones destacan: "Violencia contra mujeres en el Estado de México: cuatro discursos discordantes" en Norma Baca Tavira y Graciela Vélez Bautista (coords.), Violencia, género y la persistencia de la desigualdad en el Estado de México, Buenos Aires, Mnemosyne, pp. 105-123 (2013); "Experiencia de la Asamblea Popular de los Pueblos de Oaxaca” en María del Rosario Guerra González (coord.), Lo cotidiano y la utopia frente a los Derechos Humanos, México, Universidad Autónoma del Estado de México-Instituto de Estudios Sobre la Universidad, pp. 105-137 (2013); "El movimiento estudiantil y la teoría de los movimientos sociales", Revista Convergencia, 7 (21), Universidad Autónoma del Estado de México, Toluca, pp. 225250 (2000). 